\title{
Deformation in open collector drainage systems
}

\author{
Dilbar Abduraimova ${ }^{1}$, Makhsud Otaxonov ${ }^{1}$, Elza Tursunova $^{2}$, Davron Allayorov $^{1}$ and \\ Sarvar Melikuziyev ${ }^{1 *}$ \\ ${ }^{1}$ Tashkent Institute of Irrigation and Agricultural Mechanization Engineers, Tashkent, Republic of \\ Uzbekistan \\ ${ }^{2}$ Tashkent institute of architecture and civil engineering. Tashkent, Republic of Uzbekistan
}

\begin{abstract}
The article evaluates the hydraulic processes in the collectors which constructed in irrigated fields. Illuminated the washing processes under the influence of the flow velocity in the collector bed. In order to study the washing processes in the collector basin, are covered the results of research conducted in the self-washing collector in natural field conditions. Collector 2-K-4 in Khavas district of Syrdarya region was selected as the object of research. Given cases of changes in the project parameters as a result of washing processes in the core of the collector. Were selected 5 sections in the collector and hydraulic parameters were studied. was evaluated the effect of hydraulic processes on the collector core. The studied sections show cases of change of design parameters under the influence of hydraulic processes. Soil samples were taken from the reservoir and the mechanical composition was determined under laboratory conditions. Based on the laboratory and natural field conditions results, a special graph was developed for the design of collectors on the basis of non-washable speed.
\end{abstract}

\section{Introduction}

It is known that the role of collectors in improving the reclamation of arable land is of particular importance. This is because the collectors serve to transfer excess water generated in the control and collection ditches to subsequent collectors or to a water intake source. Sedimenting drainage of reservoirs, deterioration of water permeability have a negative impact on the entire massif. In some cases, it is common in practice that turbid particles formed as a result of leaching processes in the collector bed can accumulate in the next collector bed, in water intake sources $[1,2]$.

Analysis of the literature showed that the issues of ensuring the static and dynamic stability of irrigation canals during operation have been extensively studied by research scientists, and have been achieved certain positive results. Based on the laws of flow movement in irrigation canals and the formation of the canal, a number of recommendations have been developed to substantiate the hydraulic parameters that provide dynamic stability in the projection process, taking into account the washing and sedimentation processes $[3,4,5]$.

\footnotetext{
* Corresponding author: s.melikuziyev@tiiame.uz
} 
It is known that the movement of water flow in open streams has an effect on the formation of the stream over time. Have been studied to some extent and recommendations have been developed the laws of formation under the influence of the flow movement of irrigation canals $[4,5]$. However, the laws of bed formation under the influence of water flow movement in collectors have not been sufficiently studied. It should be noted that leaching processes are observed in the reservoirs, which are built on arable lands with a slope of the soil $\mathrm{i}=0.002$. Have been proposed and are being used a number of methods for construction collectors on the basis of non-washable velocity in the project process. Taken into account soil type, flow rate and depth are when substantiating the unwashed rate on the basis of normative documents $[3,4,5,7]$. The minimum value of the depth justifying the unwashed speed given in the normative documents is $h=0.5 \mathrm{~m}$, which cannot be used in the design of collectors. This is because most collectors are designed with a flow depth of less than $0.5 \mathrm{~m}$. One of the urgent tasks of our time is to conduct research on the study of washing processes in reservoirs, to evaluate hydraulic processes in the valley, to develop science-based design methods for the prevention of washing processes $[6,7,8]$.

\section{Solution method}

Research was conducted in natural field conditions in Khavas district of Syrdarya region, in order to study the washing processes in the collector bed. The 2-K-4 collector in Khavas district was selected as the object of research. The total length of the collector is $8.63 \mathrm{~km}$, and washing processes took place in $70 \%$ of the collector bed. The collector serves to transport excess groundwater flowing from 12,000 ha of irrigated crop fields away to collector 8-K-2. The slope varies along its length, with an average slope of $i=0.0035$ and an average depth of $5.57 \mathrm{~m}$ above ground level.

Commonly accepted methods of hydraulics and hydrology were used in the research. The cross-sections of the collector were determined using the method of measuring relative heights, and the flow velocity was determined using hydrometric vertices [9,10,11]. Identified results were mathematically statistically processed and the leaching processes in the collector bed were evaluated.

\section{Results}

As a result of research in natural field conditions, the processes of self-formation under the influence of hydrodynamic changes in sections PC-13, PC-35, PC-50, PC-64, PC-82 of the collector 2-K-4 were studied. The PC-13 section of this collector has a projection with water consumption $\mathrm{Q}=800 \mathrm{l} / \mathrm{s}$, the width of the bottom is $\mathrm{b}=3.5 \mathrm{~m}$, the depth of the stream is $\mathrm{h}=0.30 \mathrm{~m}$, the average flow velocity $\vartheta=0.72 \mathrm{~m} / \mathrm{s}$ were designed and commissioned. However, over time, leaching processes took place in the collector bed under the influence of flow. As a result of the research, the water discharge in the section PC-13 of the collector is $\mathrm{Q}=670 \mathrm{l} / \mathrm{s}$, the cross-sectional area of the flow is $\omega=0.80 \mathrm{~m}^{2}$, the average flow velocity is $\vartheta=0.83 \mathrm{~m} / \mathrm{s}$, the flow depth is $\mathrm{h}=0.50 \mathrm{~m}$ found. Because, collector core was washed and the bottom was deepened to a distance of $\Delta \mathrm{h}=0.94 \mathrm{~m}$, the width of the bottom was changed from the projected position $b=3.5 \mathrm{~m}$ to the position $\mathrm{b}=$ $1.0 \mathrm{~m}$ (Figure 1). 


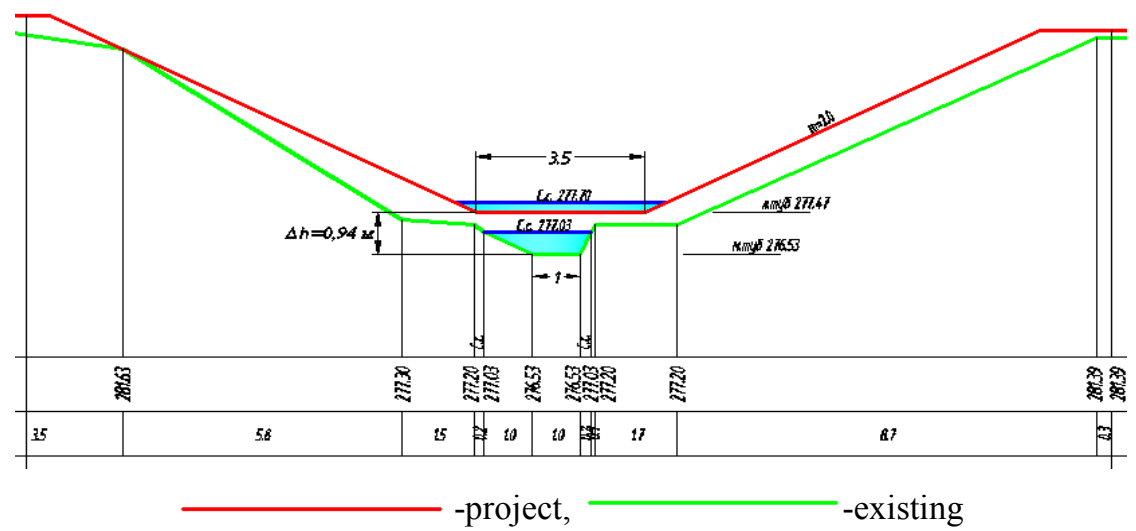

Fig. 1. Cross section of the collector (PC-13)

The PC-35 section of the collector was projected and commissioned according to the project water consumption $\mathrm{Q}=600 \mathrm{l} / \mathrm{s}$, bottom width $\mathrm{b}=3.0 \mathrm{~m}$, flow depth $\mathrm{h}=0.25 \mathrm{~m}$, average flow velocity th $=0.72 \mathrm{~m} / \mathrm{s}$. But, over time, leaching processes took place in the reservoir under the influence of flow. As a result of the research, the water consumption in the section PK-35 of the collector become to $\mathrm{Q}=570 \mathrm{l} / \mathrm{s}$, the cross-sectional area of the stream is $\omega=0.63 \mathrm{~m} 2$, the average flow velocity is $\vartheta=0.87 \mathrm{~m} / \mathrm{s}$, the flow depth is $\mathrm{h}=0.75$ $\mathrm{m}$. Collector core was washed and the bottom was deepened to a distance of $\Delta \mathrm{h}=1.00 \mathrm{~m}$, the width of the bottom changed from the design position $b=3.0 \mathrm{~m}$ to the position $b=0.5$ $\mathrm{m}$ (Figure 2).

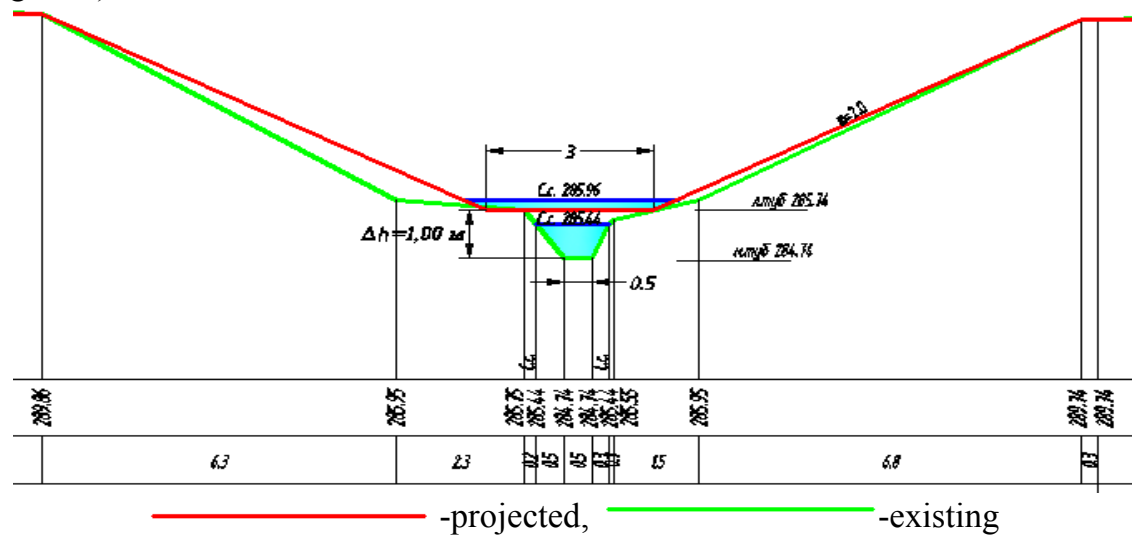

Fig. 2. Cross section of the collector (PK-35)

The PC-50 section of the collector was projected and put into operation according to the project water consumption $\mathrm{Q}=450 \mathrm{l} / \mathrm{s}$, bottom width $\mathrm{b}=3.0 \mathrm{~m}$, flow depth $\mathrm{h}=0.20 \mathrm{~m}$, average flow velocity th $=0.65 \mathrm{~m} / \mathrm{s}$. However, over time, leaching processes took place in the collector bed under the influence of flow. As a result of the research, the water discharge in the PK-50 section of the collector become to $\mathrm{Q}=470 \mathrm{l} / \mathrm{s}$, the cross-sectional area of the stream is $\omega=0.60 \mathrm{~m} 2$, the average flow velocity is $\vartheta=0.78 \mathrm{~m} / \mathrm{s}$, the flow depth is $h=0.70 \mathrm{~m}$. found to be The collector core was washed and the bottom was deepened to a distance of $\Delta \mathrm{h}=1.05 \mathrm{~m}$, the cross-sectional surface changed from a trapezoidal shape to a parabola (Fig. 3). 


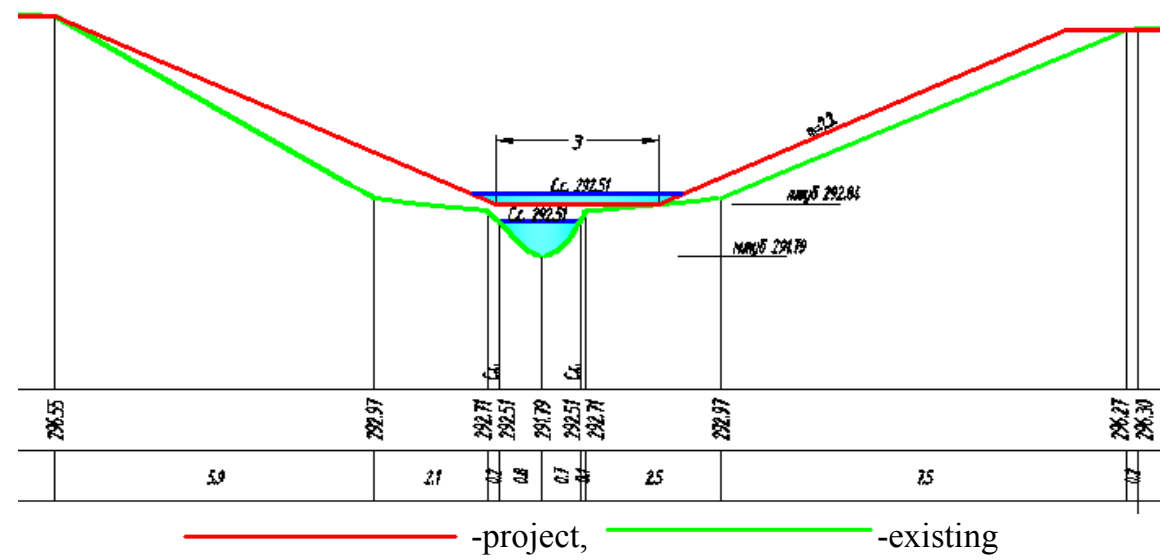

Fig. 3. Cross section of the collector (PC-50)

The PC-64 section of the collector was projected and put into operation according to the project water consumption $\mathrm{Q}=380 \mathrm{l} / \mathrm{s}$, bottom width $\mathrm{b}=3.0 \mathrm{~m}$, flow depth $\mathrm{h}=0.20 \mathrm{~m}$, average flow speed $\vartheta=0.61 \mathrm{~m} / \mathrm{s}$. submitted. However, over time, leaching processes took place in the reservoir under the influence of flow. As a result of the research, the water consumption in the section PC-64 of the collector become to $\mathrm{Q}=340 \mathrm{l} / \mathrm{s}$, the crosssectional area of the flow is $\omega=0.55 \mathrm{~m} 2$, the average flow velocity is $\vartheta=0.63 \mathrm{~m} / \mathrm{s}$, the flow depth is $\mathrm{h}=0.60 \mathrm{~m}$. Collector core was washed and the bottom was deepened to a distance of $\Delta \mathrm{h}=0.75 \mathrm{~m}$, the cross-sectional surface changed from a trapezoidal shape to a parabola (Fig. 4).

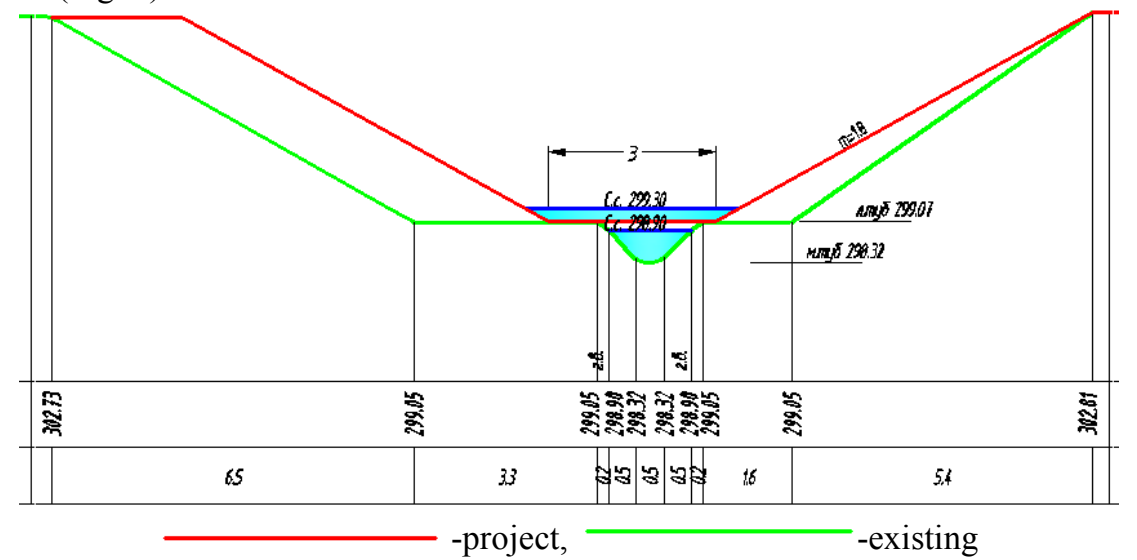

Fig. 4. Cross section of the collector (PK-64)

The PC-82 section of the collector was projected and built according to the project water consumption $\mathrm{Q}=200 \mathrm{l} / \mathrm{s}$, with bottom width $\mathrm{b}=1.5 \mathrm{~m}$, flow depth $\mathrm{h}=0.30 \mathrm{~m}$, average flow velocity $v=0.45 \mathrm{~m} / \mathrm{s}$. However, over time, leaching processes took place in the collector bed under the influence of flow. As a result of the research, the water consumption in the PC-82 section of the collector become Q $=210 \mathrm{l} / \mathrm{s}$, the cross-sectional area of the flow is $\mathrm{w}=0.50 \mathrm{~m}^{2}$, the average flow velocity is $\mathrm{v}=0.42 \mathrm{~m} / \mathrm{s}$, the flow depth is $\mathrm{h}=0.30 \mathrm{~m}$. No flushing occurred in the collector bed (Figure 5). 


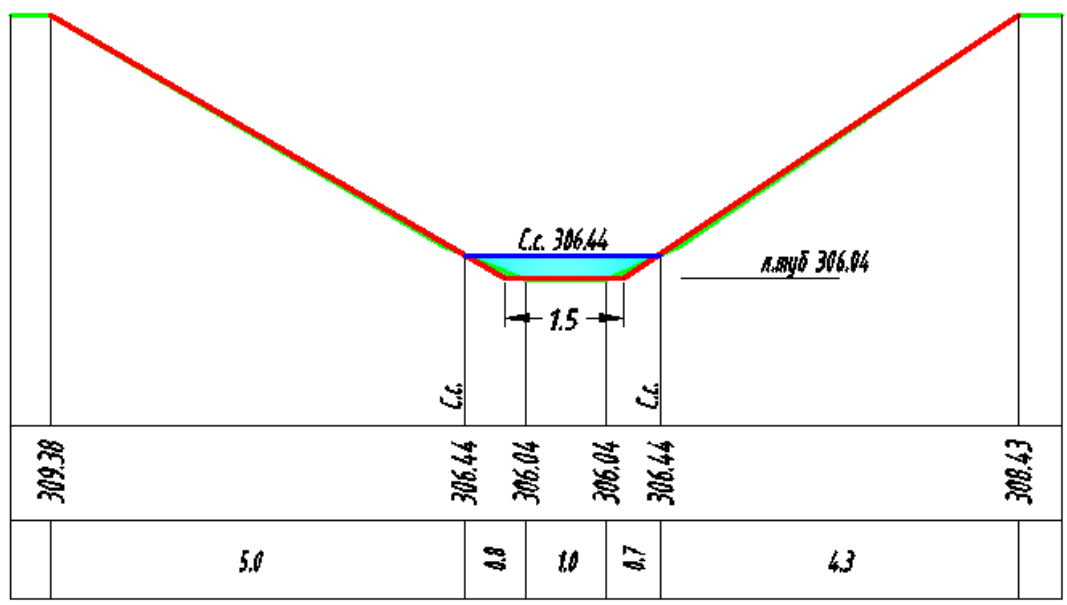

-project,

Fig. 5. Cross section of the collector (PK-82)

As a result of the research, it was found that the side walls of the collector collapsed and fell into its core, and as a result of the high flow rate, it was washed and averaged $0.9 \mathrm{~m}$ below the projected bottom.

\section{Analysis}

In order to determine the cause of washing processes in the collector, soil samples were taken and the mechanical composition was analyzed in the laboratory $[12,13,14,15]$. According to the results of the analysis, it was determined that the mechanical composition of the soil of the collector valley consists of different fractions. The results of the analysis are presented in the following tables and figures.

Table 1. Mechanical composition of the soil of the collector bed

\begin{tabular}{|c|c|c|c|c|c|c|c|c|c|c|c|}
\hline \multirow{3}{*}{ PC-13 } & $\begin{array}{c}\text { D, } \\
\text { MM }\end{array}$ & $2,0<$ & $\begin{array}{c}2,0- \\
1,0\end{array}$ & $\begin{array}{c}1,0- \\
0,5\end{array}$ & $\begin{array}{l}0,5- \\
0,25\end{array}$ & $\begin{array}{c}0,25- \\
0,10\end{array}$ & $\begin{array}{c}0,10- \\
0,05\end{array}$ & $\begin{array}{c}0,05- \\
0,01\end{array}$ & $\begin{array}{l}0,01- \\
0,005\end{array}$ & $\begin{array}{c}0,005- \\
0,001\end{array}$ & $0,001>$ \\
\hline & $\%$ & 15 & 8 & 9 & 11 & 9 & 7 & 8 & 9 & 11 & 13 \\
\hline & $\sum \%$ & 15 & 23 & 32 & 43 & 52 & 59 & 67 & 76 & 87 & 100 \\
\hline \multirow{2}{*}{ PC-35 } & $\%$ & 18 & 15 & 6 & 4 & 7 & 6 & 9 & 8 & 10 & 17 \\
\hline & $\sum \%$ & 18 & 33 & 39 & 43 & 50 & 56 & 65 & 73 & 83 & 100 \\
\hline \multirow{2}{*}{ PC-50 } & $\%$ & 13 & 19 & 8 & 5 & 12 & 5 & 7 & 6 & 13 & 12 \\
\hline & $\sum \%$ & 13 & 32 & 40 & 45 & 57 & 62 & 69 & 75 & 88 & 100 \\
\hline \multirow{2}{*}{ PC-64 } & $\%$ & 8 & 19 & 7 & 8 & 11 & 13 & 8 & 7 & 8 & 11 \\
\hline & $\sum \%$ & 8 & 27 & 34 & 42 & 53 & 66 & 74 & 81 & 89 & 100 \\
\hline \multirow{2}{*}{ PC-82 } & $\%$ & 22 & 17 & 11 & 7 & 9 & 8 & 5 & 4 & 3 & 14 \\
\hline & $\sum \%$ & 22 & 39 & 50 & 57 & 66 & 74 & 79 & 83 & 86 & 100 \\
\hline
\end{tabular}




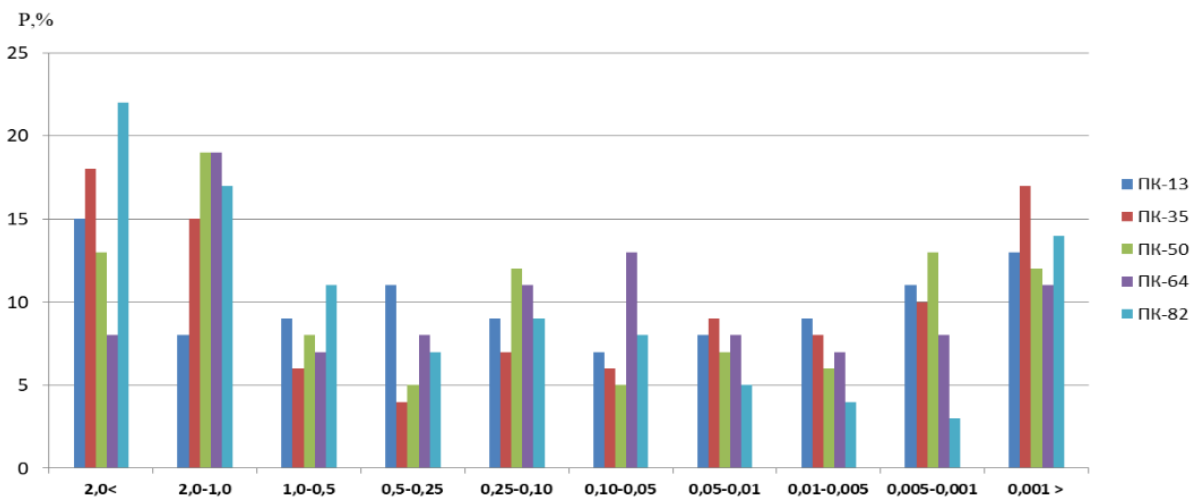

Fig. 6. Mechanical composition of collector core soil

The size of the collector bed soil varies across sections, and it is necessary to determine the average diameter when solving the problem. The average diameter of the collector core soil was determined using the following formula:

$$
D_{o}=\sum_{i=1}^{n} \frac{D_{i}}{100} P_{i}
$$

there: $D_{i}$ - is the diameter of the sedimentary particle; $P_{i}$ - percentage of this sediment particle.

According to the results, the average diameter of the collector core soil in the section PC-13 $=0.70 \mathrm{~mm}$, in the section PC-35 $D_{o}=0.95 \mathrm{~mm}$, PC-50 section $D_{o}=0.78 \mathrm{~mm}$, PC-64 section $D_{o}=0.63 \mathrm{~mm}, \mathrm{PC}-82$ section $D_{o}=1.04 \mathrm{~mm}$.

It is known that in the projection of canals, first of all, it is necessary to determine the unwashed speed on the basis of normative documents and not to exceed the specified speed of flow in the channel. When designing collectors, special attention should be paid to the design work based on the above requirements. However, in the given normative documents, for the values of the flow depth from $0.5 \mathrm{~m}$ to $5 \mathrm{~m}$ for the determination of the velocity of the self-washing, there are problems in the design of collectors on the basis of the unwashed speed $[16,17,18]$. Because in most cases in the design of collectors, the flow depth is designed at values less than $0.5 \mathrm{~m}$. Based on the results of field studies and analysis of samples taken in the laboratory, non-flushing velocity values were determined in accordance with the flow depth in the design of the collectors (Figure 7). 
h, M

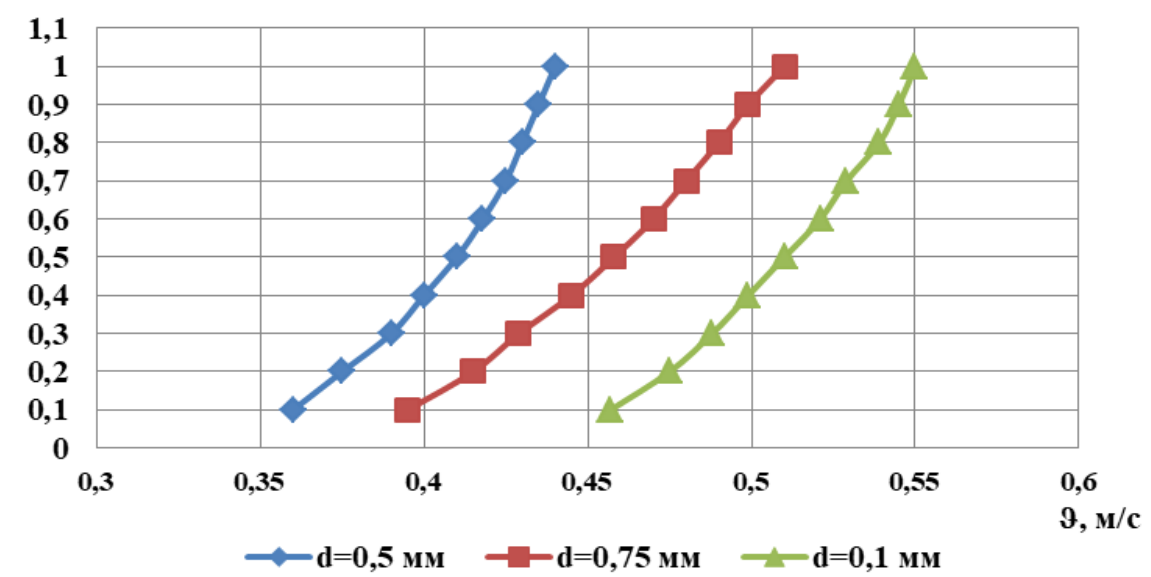

Fig. 7. Non-washable velocity detection graph in collectors

When designing collectors with an average diameter of the core soil $\mathrm{d}=0.5 \mathrm{~mm}, \mathrm{~d}=$ $0.75 \mathrm{~mm}, \mathrm{~d}=1.00 \mathrm{~mm}$, it will be possible to substantiate the unwashed velocity using this graph. The convenience of this graph is that in the design of the collectors it is possible to substantiate the unwashed velocity at values with a flow depth of $0.1 \mathrm{~m}$ to $1.0 \mathrm{~m}[19,20,21]$.

\section{Conclusion}

When reconstructing self-flushing collectors, it is necessary to substantiate the depth and velocity of the non-flushing flow before justifying the width of the flush bottom. If the width of the bottom of the collector core is not based, re-washing processes will occur. This leads to excessive costs. If the slope of the collectors is higher than $\mathrm{i}>0.002$, leaching processes will occur. Given this situation, it is necessary to substantiate the unwashed speed in the design of collectors. In the design of the collectors, a special graph was developed to justify the unwashed speed. Using this graph, it was possible to design collectors with an average diameter of the ditch soil $\mathrm{d}=0.5 \mathrm{~mm}, \mathrm{~d}=0.75 \mathrm{~mm}, \mathrm{~d}=1.00 \mathrm{~mm}$ on the basis of non-washing speed.

\section{References}

1. Aybek Arifjanov, Sherali Juraev, Luqmon Samiev, Zaytuna Ibragimova, Farruh Babajanov Determination of Filtration Strength and Initial Filtration Gradient in Soil Constructions. Jour of Adv Research in Dynamical \& Control Systems, Vol. 12, 04Special Issue, 2020. DOI: 10.5373/JARDCS/V12SP4/20201672

2. Arifjanov, A., Gapparov, F., Apakxujaeva, T., Xoshimov, S. Determination of reduction of useful volume in water reservoirs due to sedimentation (2020) IOP Conference Series: Earth and Environmental Science, 614 (1).DOI: 10.1088/1755$1315 / 614 / 1 / 012079$

3. Arifjanov, A., Xodjiyev, N., Jurayev, S., Kurbanov, K., Samiev, L. Increasing heat efficiency by changing the section area of the heat transfer pipelines (2020) IOP Conference Series: Materials Science and Engineering, 869 (4). DOI: 10.1088/1757$899 \mathrm{X} / 869 / 4 / 042019$ 
4. Arifjanov, A., Fatxullaev, A. Natural Studies for Forming Stable Channel Sections (2020) Journal of Physics: Conference Series, 1425 (1). DOI: 10.1088/1742$6596 / 1425 / 1 / 012025$

5. Arifjanov, A., Juraev, S., Samiev, L., Ibragimova, Z., Babajanov, F. Determination of filtration strength and initial filtration gradient in soil constructions. (2020) Journal of Advanced Research in Dynamical and Control Systems, 12 (4 Special Issue), pp. 18601864. DOI: $10.5373 / J A R D C S / V 12 S P 4 / 20201672$

6. Arifjanov, A., Apakhodjaeva, T., Akmalov, S. Calculation of losses for transpiration in water reservoirs with using new computer technologies. (2019) International Conference on Information Science and Communications Technologies: Applications, Trends and Opportunities, ICISCT 2019. DOI: 10.1109/ICISCT47635.2019.9011883

7. Arifjanov, A., Samiev, L., Akmalov, S. Dependence of fractional structure of river sediments on chemical composition. (2019) International Journal of Innovative Technology and Exploring Engineering, 9 (1), pp. 2646-2649. DOI: 10.35940/ijitee.L2944.119119

8. Arifzhanov, A.M. Method for calculation of the distribution of drift particles in variable section beds (VSB) (2004) Gidrotekhnicheskoe Stroitel'stvo, (2), pp. 44-45.

9. Arifzhanov, A.M. Distribution of Suspended Sediment Particles in a Steady-State Flow. (2001) Water Resources, 28 (2), pp. 164-166. DOI: 10.1023/A:1010375500148

10. Fatxulloyev, A., Abduraimova, D., Otakhonov, M., Atakulov, D., Samiev, L. Method designing of open drainages (2020) IOP Conference Series: Materials Science and Engineering, 883 (1),.DOI: 10.1088/1757-899X/883/1/012047

11. Fatxulloyev, A., Allayorov, D., Otakhonov, M.Study of hydraulic parameters for concreting channels (2020) IOP Conference Series: Earth and Environmental Science, 614 (1).DOI: 10.1088/1755-1315/614/1/012054

12. Fatxulloyev, A., Gafarova, A., Otakhonov, M., Allayorov, D. The hydraulic efficiency of the soil channels (2020) IOP Conference Series: Materials Science and Engineering, 883 (1). DOI: $10.1088 / 1757-899 X / 883 / 1 / 012042$

13. Muratov, A., Muratov, O., Melikuziyev, S.Operational control of energy consumptions of reclamation machines (2020) IOP Conference Series: Earth and Environmental Science, 614 (1). DOI: 10.1088/1755-1315/614/1/012042

14. Arifjanov, A., Rakhimov, K., Abduraimova, D., Babaev, A., Melikuziyev, S. Hydrotransport of river sediments in hydroelelators. (2020) IOP Conference Series: Materials Science and Engineering, 869 (7). DOI: 10.1088/1757-899X/869/7/072003

15. Muratov, A., Melikuziev, S. Technology of formation of combined products of meliorative purpose (2020) IOP Conference Series: Materials Science and Engineering, 883 (1). DOI: $10.1088 / 1757-899 \mathrm{X} / 883 / 1 / 012060$

16. Samiyev, L., Allayorov, D., Atakulov, D., Babajanov, F. The influence of sedimentation reservoir on hydraulic parameters of irrigation channels (2020) IOP Conference Series: Materials Science and Engineering, 883 (1), DOI: 10.1088/1757899X/883/1/012031

17. M.M. Mirsaidov, R.A. Abdikarimov, D.A. Khodzhaev. Dynamics of a viscoelastic plate carrying concentrated mass with account of physical nonlinearity of material. part 1. mathematical model, solution method and computational algorithm. PNRPU Mechanics Bulletin 2 (2019) 143-153 P

18. Averyanov S.F. Orositelniye melioratsii. [Irrigation amelioration]. Kolos. Moskov, 1973.-148, 159 P. (In Russian) 
19. Fatxulloev, A., Gafarova, A. Study of the process of cultivation in soil fertile irrigation $\begin{array}{lllll}\text { canals. E3S Web of Conferences, 2019, 97, } 05025 & \end{array}$ https://doi.org/10.1051/e3sconf/20199705025

20. Fatkhulloev, A., Gafarova, A., Hamraqulov, J. The Importance of Mobile Applications in the Use of Standard Water Measurements. International Conference on Information Science and Communications Technologies: Applications, Trends and Opportunities, ICISCT 2019, 2019, 9011816 doi: 10.1109/ICISCT47635.2019.9011816

21. Fatxulloyev A, Gafarova A, Hamroqulov J. Improvement of water accounting for irrigation systems. IOP Conference Series: Materials Science and Engineering, 2021, 1030012145 doi:10.1088/1757-899X/1030/1/012145 